\title{
Olive tree, Olea europaea L., leaves as a bioindicator of atmospheric PCB contamination
}

\author{
Sait C. Sofuoglu • Burak Yayla • Pinar Kavcar • \\ Duygu Ates • Cafer Turgut • Aysun Sofuoglu
}

Received: 23 January 2013 / Accepted: 12 March 2013 /Published online: 16 April 2013

(C) Springer-Verlag Berlin Heidelberg 2013

\begin{abstract}
Olive tree leaf samples were collected to investigate their possible use for biomonitoring of lipophilic toxic substances. The samples were analyzed for 28 polychlorinated biphenyls (PCB) congeners. Twelve congeners were detected in the samples. PCB-60, 77, 81, 89, 105, 114, and 153 were the most frequently detected congeners ranging from $32 \%$ for PCB-52 to $97 \%$ for PCB-81. $\Sigma_{12}$ PCBs concentration varied from below detection limit to $248 \mathrm{ng} / \mathrm{g}$ wet weight in the sampling area, while the mean congener concentrations ranged from $0.06 \mathrm{ng} / \mathrm{g}(\mathrm{PCB}-128+167)$ to $64.2 \mathrm{ng} / \mathrm{g}$ wet weight (PCB-60). Constructed concentration maps showed that olive tree leaves can be employed for the estimation of spatial distrubution of these congeners.
\end{abstract}

Keywords Biomonitoring - Olive tree leaves · PCBs · Spatial distribution

\section{Introduction}

Vegetation has been used as bioindicators of persistent organic pollutants (POPs) in the atmosphere (Blais et al. 2003; Chen et al. 2006; Eriksson et al. 1989; Holoubek et al. 2000;

Responsible editor: Leif Kronberg

S. C. Sofuoglu $\cdot$ A. Sofuoglu $(\square)$

Department of Chemical Engineering and Environmental

Research Center, Izmir Institute of Technology, Gulbahce,

Urla 35430 Izmir, Turkey

e-mail: aysunsofuoglu@iyte.edu.tr

B. Yayla $\cdot$ P. Kavcar

Department of Chemical Engineering,

Izmir Institute of Technology, Gulbahce,

Urla 35430 Izmir, Turkey

D. Ates $\cdot$ C. Turgut

Faculty of Agriculture, Adnan Menderes University,

Aydin, Turkey
Klánová et al. 2009; Kožul and Romanić 2008; Mast et al. 2012; Tato et al. 2011; Wyrzykowska et al. 2007), which includes grass, tree bark, leaves of an Australian native tree (Melaleuca leucadendra), spruce needles, pine needles, and lichens/mosses. The last two have been the most preferred ones. The reason for that is lichens and mosses do not have a root system so that uptake occurs only via the atmosphere, while pine needles have a waxy surface that enables accumulation of organic contaminants up to 3 years from both gas phase and the particle phase to a certain extent (Holoubek et al. 2000; Klánová et al. 2009). The major factor for the preference is that these plants can be found all around the Earth, even at remote sites. However, other evergreen species may be more appropriate for certain geographic areas where they dominantly cover large areas. Leaves of a native tree (M. leucadendra) were used as an indicator for polychlorinated dibenzodioxins and dibenzofurans and polycyclic aromatic hydrocarbons (PAHs) in Brisbane, Australia (Müller et al. 2001). The Mediterranean region is such an area where wild and domestic olive trees are abundant. Previously, we have shown that olive tree (Olea europea L.) leaves can be utilized for biomonitoring of trace elements (Turan et al. 2011).

Olive tree is commonly found all around the Mediterranean, both wild and cultivated, because of its drought tolerance and capacity to grow in shallow, poor-quality soils even in arid areas. One of its drought tolerance strategies to overcome typical Mediterranean long dry periods is the high amounts of cuticular wax (Leon and Bukovac 1978) that significantly increases diffusion resistance of the cuticular membrane and allows transpiration to take place only through the stomata (Fernández and Moreno 1999). The lipophilic surface facilitates accumulation of hydrophobic chemicals (Sabljic et al. 1990) over multiple years because olive tree is evergreen, and it can have up to 3-year-old leaves with a mean one-side leaf surface area of $359 \mathrm{~mm}^{2}$ (Fernández and Moreno 1999). These properties show that olive tree leaves would potentially 
make very good passive samplers of POPs across the Mediterranean countries.

Olive tree leaves have not been studied as a bioindicator of atmospheric POPs. The objective of this study was to investigate the applicability of olive tree leaves for biomonitoring and assessment of atmospheric POPs as in the case of polychlorinated biphenyls (PCBs) in the province of Aydin, Turkey, where they are indigenous and cultivated.

\section{Materials and methods}

Olive tree (O. europaea L.) leaves were collected from 40 sampling sites in the province of Aydin from September to November in 2008. The sampling sites were chosen randomly to represent the province of Aydin for mapping purposes, using topographic $(1 / 25,000)$ and land use $(1 / 100,000)$ maps, and Landsat ETM+images from years 2006 and 2007. However, it was made sure that no other agricultural activity had not been conducted at the site or the neighboring fields. The leaves were collected from five to ten trees at each sampling site. The leaves were collected from both the upper and the lower parts of trees. After all were thoroughly mixed, $300 \mathrm{~g}$ was taken from the mix. The samples were kept in the freezer at $-20{ }^{\circ} \mathrm{C}$ until sample preparation for extraction.

For all analyses, cleaning, and sample procedures, trace organic and chemical-free ultrapure water (Millipore Elix 5) and high-purity solvents were used. Olive leaves were cut into small pieces to fit $3 \mathrm{~g}$ (wet weight) into 40-ml amber glass vials before the addition of $10 \mathrm{ml}$ of ultrapure water, $10 \mathrm{ml}$ of acetonitrile (for chromatography Merck KGaA, Germany), and a spike of surrogate standard. Then, the mixture was shredded with Turax after which $4 \mathrm{~g}$ of $\mathrm{MgSO}_{4}$ (anhydrous; Merck KGaA, Germany) and $1 \mathrm{~g}$ of $\mathrm{NaCl}$ (Riedel de Haen, Germany) were added. The samples were manually shaken for a minute and centrifuged at $30,000 \mathrm{rpm}$ for $5 \mathrm{~min}$. The supernatant was taken, then $1.2 \mathrm{mg} \mathrm{MgSO}_{4}$ was added, and it was kept in a vortex for $30 \mathrm{~s}$. Following another $5 \mathrm{~min}$. of centrifuging at 30,000 rpm, the supernatant was taken to exchange solvent to hexane and reduce its volume to $2 \mathrm{ml}$ under a gentle $\mathrm{N}_{2}$ stream.

The cleanup procedure for the enhancement of PCBs from extracted solution was described elsewhere in detail (Tasdemir et al. 2004) for dry deposition samples collected on greased surfaces. Briefly, concentrated samples were cleaned and fractioned using an alumina-silicic acid column containing $3 \mathrm{~g}$ of silicic acid (Merck KGaA, Germany) overlaid with $2 \mathrm{~g}$ of neutral alumina (SigmaAldrich, Germany) and topped with $0.5 \mathrm{~g}$ of anhydrous sodium sulfate (Merck KGaA, Germany). Deactivation of silicic acid and alumina was performed by manually shaking with 4.5 and $6 \%$ ultrapure water, respectively. Deactivated silicic acid and alumina were prepared daily and kept at room temperature for an hour prior to use. The cleanup column was prewashed with $20 \mathrm{ml}$ dichloromethane for gas chromatography (Merck KGaA, Germany) followed by $20 \mathrm{ml}$ petroleum ether (PE) for analysis (Merck KGaA, Germany). The sample in hexane was added into the column with a rinse of $5 \mathrm{ml} \mathrm{PE}$. The eluent was collected in a vial. After pass-through was complete, $30 \mathrm{ml} \mathrm{PE}$ was added into the column, collecting the eluent in the same vial. This fraction contains the PCBs. The solvent was exchanged into hexane before the final sample volume was adjusted to $\sim 1 \mathrm{ml}$ under a gentle stream of $\mathrm{N}_{2}$. The samples were then transferred into 2-ml amber vials crimp-capped with teflon-faced septa and stored in the dark at $-20{ }^{\circ} \mathrm{C}$ until analysis.

The samples were analyzed using a gas chromatograph (Thermo Trace GC Ultra) equipped with a mass spectrometry (MS) detector (Thermo DSQII) to identify and quantify PCBs. The system was run at electron ionization mode. The programmable temperature vaporizer inlet was operated at splitless mode. Identification of the compounds eluting from the GC column was accomplished by comparing their measured mass spectra and retention times to reference spectra and retention times in a database (Xcalibur, Thermo). "WHO/NIST/NOAA Congener List" analytical standard (AccuStandard, C-WNN) containing 28 PCBs $(8,18,28,52,44,60,77,81,101,105$, $114,118,123,126,128,138,153,156,157,167,169,170$, $180,187,189,195,206$, and 209) was used as the calibration standard. Selective ion monitoring program was employed to increase instrument sensitivity.

QA/QC evaluations included initial demonstration of accuracy and precision of the GC-MS system, continuing calibration check, and routine analyses of laboratory blanks. In addition, MS autotune was performed every day before introducing the samples. Five-point calibrations were conducted, and $R^{2}$ values were $>0.99$ for each PCB congener. Laboratory blanks were prepared in the laboratory to determine possible system background contamination, and the samples were blank corrected. A surrogate standard containing PCB-14, 65, and 166 was added to samples prior to processing (shredding, extraction, cleanup, fractionation, and volume reduction) to determine method recovery through all steps of the sample processing. Recoveries ( $n=40)$ were $82 \pm 12 \%$ (mean \pm standard deviation) for PCB-14, 104 $\pm 24 \%$ for PCB-65, and 107 $\pm 13 \%$ for PCB166. Additionally, two sets of triplicates were processed and analyzed to determine variation due to sample preparation and processing. Relative standard deviation of the first set ranged from $9.6 \%$ for PCB-101 to $0.6 \%$ for PCB-60 among the 
detected congeners, while it was $0.6 \%$ for PCB-105 and 8 . $7 \%$ for PCB- $128+167$.

\section{Results and discussion}

Out of the 28 analyzed PCBs, PCB-60, 77, 81, 89, 105, 114 , and 153 were the most widely detected PCB congeners, ranging from $32 \%$ (PCB-52) to $97 \%$ (PCB-81) of the samples. Samples below detection limit (BDL) were censored with half the detection limit. The mean congener concentrations ranged from $0.06 \mathrm{ng} / \mathrm{g}$ (PCB$128+167)$ to $64.2 \mathrm{ng} / \mathrm{g}$ wet weight (PCB-60). Descriptive statistics are presented in Table 1. Values of the skewness statistic were $\geq 2$ for PCB-8, 52, and $128+$ 167 , indicating that their distributions were right skewed. Concentrations of total PCBs $\left(\Sigma_{12} \mathrm{PCBs}\right)$ ranged from $\mathrm{BDL}$ to $248 \mathrm{ng} / \mathrm{g}$ among the 40 sampling locations. Based on the mean values, most of the contribution to the total concentration was from PCB-60 (86 \%) followed by PCB-105 (6.5\%), and PCB-153 (2.1 \%). The mean contribution of the remaining congeners was $<1 \%$ each. The assessment of degree of contamination can be conducted using normalized concentrations (pollution factor, PF) defined as the ratio of the determined contamination (concentration in a polluted area) to the base-level contamination (concentration in an unpolluted, background site) by Elik et al. (2000), which is a modification of the bioindication factor (Schulz et al. 1999). Since all congeners had at least a BDL site, the PF values are $\gg 10$ for all congeners at all sites other than those of BDLs (ranging from 74 for PCB-128+167 to 45,000 for PCB-60), indicating serious contamination levels at least at one site. So, the detection percentages (Table 1) roughly reflect the degree of spatial contamination in the study area. It would not be appropriate to compare concentrations measured in this study to the literature because there is no other study that used olive leaves as bioindicators. However, the PCB levels measured in spruce/pine needles, a widely employed bioindicator with cuticular wax, are worth mentioning. The concentrations were generally low $(<1 \mathrm{ng} / \mathrm{g})$ for measured individual congeners at remote sites (PCB-28, 52, 101, 138, 153, and 180; Klánová et al. 2009) and in a background area in Czech Republic (PCB-28, 52, and 101; Holoubek et al. 2000), in Dalian, China (summation of PCBs with the same degree of chlorination; Chen et al. 2006) and in Zagreb, Croatia (17 of 20 PCB congeners; Kožul and Romanić 2008). The concentrations were generally $>1 \mathrm{ng} / \mathrm{g}$ for PCB-28, 52, and 60 in Zagreb, Croatia (Kožul and Romanić 2008), and for PCB-28, 52, $60,74,101,138$, and 153 along the Adriatic coast, Croatia (Romanić and Klinčić 2012); up to $50 \mathrm{ng} / \mathrm{g}$ for total PCBs in heavily industrialized and populated areas of Poland (Falandysz et al. 2012; Wyrzykowska et al. 2007); up to $270 \mathrm{ng} / \mathrm{g}$ with an average of $93 \mathrm{ng} / \mathrm{g}$ for $\Sigma_{15}$ PCBs in Beijing, China (Xu et al. 2004); and up to $128 \mathrm{ng} / \mathrm{g}$ for total PCBs around a hazardous waste incinerator in Canada (Blais et al. 2003).

A Spearman's rank correlation matrix was constructed (Table 2). Correlations among all congeners were significant at $\alpha=0.01$ level except for PCB-81 and PCB-114 which did not correlate with any other congener. Values of the significant correlation coefficients ranged from 0 . 43 (PCB-8 and PCB-52) to 0.94 (PCB-77 and PCB-153). Therefore, factor analysis was applied to further infer on commonalities of their sources. Varimax-rotated principal component analysis was used. Eigen values $>1$ and loadings $>0.45$ were regarded as significant. The analysis resulted in three factors (Table 3) which may imply that contamination of PCB-60, 77, 105, 153, 128+167, and 180 probably was from a common source, whereas contamination of PCB-52, 101, and 8 was from another source. PCB-114 and 81 probably originated from some other source. Figure 1 presents the constructed spatial contamination distribution maps for the 12 congeners and $\Sigma_{12} \mathrm{PCBs}$. The maps are presented in three groups considering the results of the factor analysis. The maps seem visually similar within the three groups, in agreement with the results of the factor analysis that there

Table 1 Descriptive statistics for PCB congener concentrations (in nanogram per gram wet weight)

\begin{tabular}{|c|c|c|c|c|c|c|c|c|c|c|c|c|}
\hline & \multicolumn{12}{|c|}{ Congener } \\
\hline & 8 & 52 & 60 & 77 & 81 & 101 & 105 & 114 & $128+167$ & 153 & 180 & $\Sigma_{12} \mathrm{PCBs}$ \\
\hline Mean & 0.59 & 0.64 & 64.2 & 0.30 & 0.44 & 0.60 & 5.07 & 0.48 & 0.06 & 1.56 & 0.21 & 74.3 \\
\hline Median & 0.28 & 0.00 & 60.9 & 0.35 & 0.32 & 0.00 & 4.44 & 0.39 & 0.05 & 1.65 & 0.22 & 68.7 \\
\hline Maximum & 7.47 & 7.04 & 226 & 0.77 & 1.68 & 3.53 & 12.5 & 1.16 & 0.37 & 3.91 & 0.57 & 248 \\
\hline $\mathrm{SD}$ & 1.22 & 1.43 & 48.8 & 0.22 & 0.36 & 1.00 & 3.66 & 0.30 & 0.07 & 1.25 & 0.16 & 55.4 \\
\hline Skewness & 5.13 & 3.23 & 0.91 & 0.22 & 1.81 & 1.54 & 0.19 & 0.39 & 2.00 & 0.24 & 0.38 & 0.76 \\
\hline$\%$ Detected & 74 & 32 & 95 & 92 & 97 & 42 & 95 & 89 & 66 & 87 & 79 & \\
\hline
\end{tabular}


Table 2 Spearman's correlation matrix

\begin{tabular}{|c|c|c|c|c|c|c|c|c|c|c|}
\hline & PCB-8 & & & & & & & & & \\
\hline PCB 52 & $0.43 * *$ & PCB-52 & & & & & & & & \\
\hline PCB 60 & $0.68 * *$ & $0.70 * *$ & PCB-60 & & & & & & & \\
\hline PCB 77 & $0.69^{* *}$ & $0.60 * *$ & $0.84 * *$ & PCB-77 & & & & & & \\
\hline PCB 81 & $0.33^{*}$ & 0.31 & 0.07 & $0.34 *$ & PCB-81 & & & & & \\
\hline PCB 101 & $0.48 * *$ & $0.77 * *$ & $0.71 * *$ & $0.59 * *$ & $0.32 *$ & PCB-101 & & & & \\
\hline PCB 105 & $0.74 * *$ & $0.68 * *$ & $0.86^{* *}$ & $0.88 * *$ & $0.45^{* *}$ & $0.71 * *$ & PCB-105 & & & \\
\hline PCB 114 & 0.09 & 0.17 & $0.33 *$ & 0.23 & 0.25 & 0.11 & 0.27 & PCB-114 & & \\
\hline PCB 153 & $0.78 * *$ & $0.61 * *$ & $0.87 * *$ & $0.94 * *$ & $0.39 *$ & $0.59 * *$ & $0.91 * *$ & 0.20 & PCB-153 & \\
\hline РCB $128+167$ & $0.69 * *$ & $0.65 * *$ & $0.81 * *$ & $0.80^{* *}$ & $0.42 * *$ & $0.63 * *$ & $0.87 * *$ & 0.07 & $0.84 * *$ & PCB-128+167 \\
\hline PCB 180 & $0.56^{* *}$ & $0.57 * *$ & $0.78 * *$ & $0.76^{* *}$ & $0.40 *$ & $0.65^{* *}$ & $0.82 * *$ & 0.30 & $0.79 * *$ & $0.75^{* *}$ \\
\hline
\end{tabular}

${ }^{*} p \leq 0.05 ;{ }^{*} p \leq 0.01$

were probably three different sources for the most detected 12 congeners. Factor- 1 congeners seem to have four main contamination locations, while factor-2 congeners seem to have seperate single contamination locations, two of which coincide with factor-1 locations (PCB-8 and PCB-101). None of the contamination locations for congeners of the three factors has a common or specific characteristic that would help guess the possible source(s). Hence, a study specifically designed to identify the possible sources, which should also employ soil analyses that include parameters other than PCBs that may be used as clues, is needed. Variation in PCB concentrations were associated with industrial activities and population density (Falandysz et al. 2012; Schuster et al. 2010). However, relatively high concentrations may be observed at nonindustrial rural sites probably due to past site activity, waste dumping (leakage from materials or products that contain $\mathrm{PCBs}$ ), vegetation fires, and anthropogenic thermal processes such as incidental and intentional fires and combustion processes (Falandysz et al. 2012). PCB-60 is one of the main components of Kanechlor-400 with $6.4 \%$; PCB-105 is found at a significant proportion only in Sovol (1.6\%) among all technical formulations studied; and PCB-153 is a major component in Aroclor-1260, Delor-106, Kanechlor-600, and Clophen-A60 with $>10 \%$ (Wyrzykowska et al. 2006). Considering concentration levels of these three congeners in olive leaves (PCB-60 $>$ PCB-105 $>$ PCB-153) , contamination may have resulted from either Aroclor1242, Kanechlor-300 or -400 , or Delor-103 technical formulations, if the source was a leakage from a material or a product. However, no formulations were produced in Turkey, and materials and products that contained PCBs were imported from several countries, which makes it very difficult to even speculate about the sources. The province of Aydın is mainly dependent on agriculture; likely sources may be the fires and the pesticides that contained PCBs as extenders. Aroclor-1254 was reported to be used for this purpose (ATSDR 2000), which was also reported (Kodavanti et al. 2001) to have variable toxic non-ortho congener content: one of the two lots that were analyzed had PCB-77, 81, and 126 at higher proportions than the other.

Overall, the results of this PCB case study showed that olive tree leaves can potentially be used for the biomonitoring and assessment of atmospheric POPs in the Mediterranean and other regions where they are indigenous and cultivated. Its potential should be verified by further studies that will investigate their (1) sampling rates for gas and particulate phases at different geographical settings with varying atmospheric concentrations such as urban, industrial, and rural; (2) agreement with active air sampling results; (3) degradation in

Table 3 Scores of varimax rotated factor analysis

\begin{tabular}{llll}
\hline & Factor 1 & Factor 2 & Factor 3 \\
\hline PCB 153 & 0.94 & & \\
PCB 77 & 0.92 & & \\
PCB 105 & 0.87 & & \\
PCB 128+167 & 0.84 & & \\
PCB 60 & 0.81 & & \\
PCB 180 & 0.68 & & \\
PCB 52 & & 0.92 & \\
PCB 101 & & 0.79 & 0.82 \\
PCB 8 & & 0.41 & 0.65 \\
PCB 114 & & & 9 \\
PCB 81 & & 12 & \\
Variation (\%) & 55 & & \\
\hline
\end{tabular}



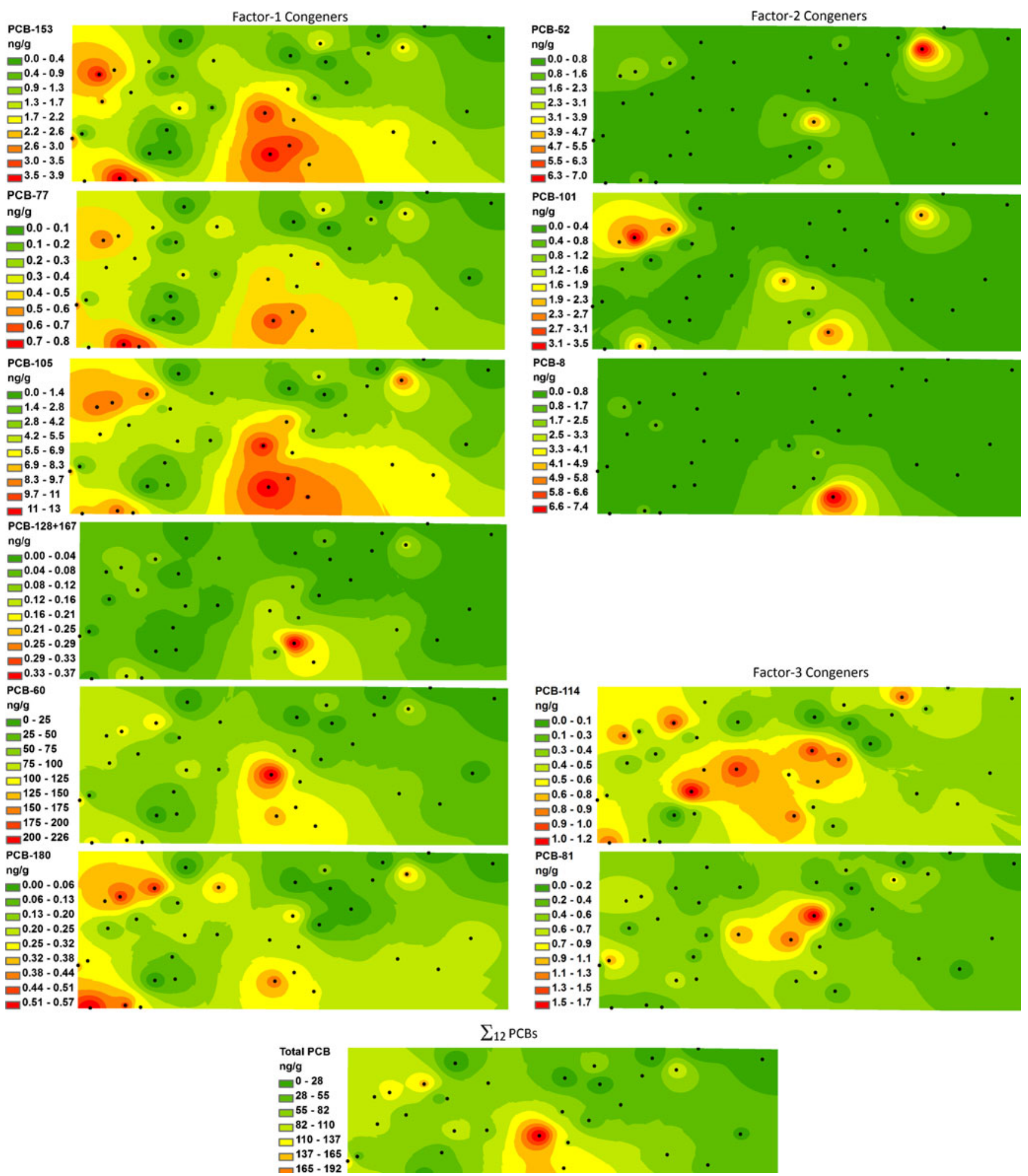

Fig. 1 PCB congener and $\Sigma_{12} \mathrm{PCB}$ contamination distribution maps

the cuticular wax; and (4) applicability to the other common POPs such as PBDEs, OCPs, and PAHs. Research is also needed to develop a reference material for improvement in QA/QC and to investigate the effect of leaf age, partitioning from contaminated soil to the roots, tree biological processes, etc. 
Acknowledgments Olive leaves were collected in a research project supported by the Scientific and Technical Research Council of Turkey (grant no. 1070170).

Conflict of interest The authors declare that there are no conflicts of interest.

\section{References}

ATSDR (2000) Toxicological profile for polychlorinated biphenyls (PCBs), US Department of Health and Human Services. Agency for Toxic Substances and Disease Registry, Atlanta

Blais JM, Froese KL, Kimpe LE, Muir DCG, Backus S, Comba M, Schindler DW (2003) Assessment and characterization of polychlorinated biphenyls near a hazardous waste incinerator: analysis of vegetation, snow, and sediments. Environ Toxicol Chem 22:126-133

Chen J, Zhao H, Gao L, Henkelmann B, Schramm KW (2006) Atmospheric PCDD/F and PCB levels implicated by pine (Cedrus deodara) needles at Dalian, China. Environ Pollut 144:510-515

Elik A, Akçay M, Sökmen M (2000) Ultrasonic leaching of biocollectors for heavy metal analysis. Int $\mathrm{J}$ Environ Anal Chem $77: 133-145$

Eriksson G, Jensen S, Kylin H, Strachan W (1989) The pine needle as a monitor of atmospheric pollution. Nature 341:42-44

Falandysz J, Orlikowska A, Jarzyńska G, Bochentin I, Wyrzykowska B, Drewnowska M, Hanari N, Horii Y, Yamashita N (2012) Levels and sources of planar and non-planar PCBs in pine needles across Poland. J Environ Sci Health A 47:688-703

Fernández JE, Moreno F (1999) Water use by the olive tree. J Crop Prod 2:101-162

Holoubek I, Kořínek P, Šeda Z, Schneiderová E, Holoubková I, Pacl A, Tř́ska J, Cudlín P, Č́slavský J (2000) The use of mosses and pine needles to detect persistent organic pollutants at local and regional scales. Environ Pollut 109:283-292

Klánová J, Čupr P, Baráková D, Šeda Z, Anděl P, Holoubek I (2009) Can pine needles indicate trends in the air pollution levels at remote sites? Environ Pollut 157:3248-3254

Kodavanti PRS, Kannan N, Yamashita N, Derr-Yellin EC, Ward TR, Burgin DE, Tilson HA, Birnbaum LS (2001) Differential effects of two lots of Aroclor 1254: congener-specific analysis and neurochemical end points. Environ Health Perspect 109:1153-1161

Kožul D, Romanić S (2008) Distribution of organochlorine compounds in pine needles collected in Zagreb. Bull Environ Contam Toxicol 81:339-342
Leon JM, Bukovac MJ (1978) Cuticle development and surface morphology of olive leaves with reference to penetration of foliarapplied chemicals. J Am Soc Hortic Sci 103:465-472

Mast MA, Alvarez DA, Zaugg SD (2012) Deposition and accumulation of airborne organic contaminants in Yosemite National Park, California. Environ Toxicol Chem 31:524-533

Müller JF, Hawker DW, McLachlan MS, Connell DW (2001) PAHs, $\mathrm{PCDD} / \mathrm{Fs}$, PCBs and $\mathrm{HCB}$ in leaves from Brisbane, Australia. Chemosphere 43:507-515

Romanić SH, Klinčić D (2012) Organochlorine compounds in pine needles from Croatia. Bull Environ Contam Toxicol 88:838-841

Sabljic A, Guesten H, Schoenherr J, Riederer M (1990) Modeling plant uptake of airborne organic chemicals. 1. Plant cuticle/water partitioning and molecular connectivity. Environ Sci Technol 24:1321-1326

Schulz H, Popp P, Huhn G, Stärk HJ, Schüürmann G (1999) Biomonitoring of airborne inorganic and organic pollutants by means of pine tree barks. I. Temporal and spatial variations. Sci Total Environ 232:49-58

Schuster JK, Gioia R, Sweetman AJ, Jones KC (2010) Temporal trends and controlling factors for polychlorinated biphenyls in the UK atmosphere (1991-2008). Environ Sci Technol 44:80688074

Tasdemir Y, Odabasi M, Vardar N, Sofuoglu A, Murphy TJ, Holsen TM (2004) Dry deposition fluxes and velocities of polychlorinated biphenyls (PCBs) associated with particles. Atmos Environ 38:2447-2456

Tato L, Tremolada P, Ballabio C, Guazzoni N, Parolini M, Caccianiga M, Binelli A (2011) Seasonal and spatial variability of polychlorinated biphenyls (PCBs) in vegetation and cow milk from a high altitude pasture in the Italian Alps. Environ Pollut 159:2656-2664

Turan D, Kocahakimoglu C, Kavcar P, Gaygisiz H, Atatanir L, Turgut C, Sofuoglu SC (2011) The use of olive tree (Olea europaea L.) leaves as a bioindicator for environmental pollution in the Province of Aydın, Turkey. Environ Sci Pollut Res 18:355-364

Wyrzykowska B, Bochentin I, Hanari N, Orlikowska A, Falandysz J, Yuichi H, Yamashita N (2006) Source determination of highly chlorinated biphenyl isomers in pine needles - comparison to several PCB preparations. Environ Pollut 143:46-59

Wyrzykowska B, Hanari N, Orlikowska A, Bochentin I, Rostkowski P, Falandysz J, Taniyasu S, Horii Y, Jiang Q, Yamashita N (2007) Polychlorinated biphenyls and -naphthalenes in pine needles and soil from Poland - concentrations and patterns in view of longterm environmental monitoring. Chemosphere 67:1877-1886

Xu D, Deng L, Chai Z, Mao X (2004) Organohalogenated compounds in pine needles from Beijing City, China. Chemosphere 57:13431353 